\title{
Hurto de infancias
}

\author{
Marie-Astrid Dupret*
}

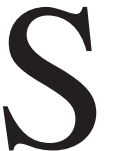

i hay una enseñanza fundamental del psicoanálisis, es que los padres y los adultos en general, por despreocupación, por egoísmo o por ignorancia, pueden perjudicar e incluso dañar las posibilidades del desarrollo psíquico de sus hijos. Para evitar muchas dramáticas historias de niñez aniquilada, "es necesario romper, o por lo menos intentar romper, esta cadena por la cual una generación destruye a la siguiente", como dice Bettelheim ${ }^{1 .}$

Con la tendencia posmoderna de "hacer hablar a los actores", se han multiplicados foros y encuentros de distintas índoles para escuchar "la opinión de las niñas, niños y adolescentes"- como en Cuenca, en el 2004. Y para el efecto se gastan sumas considerables de dinero, un dinero tan lamentablemente escaso para la educación o para la salud de los mismos niños. A pesar de esas fuertes inversiones, los organizadores no parecen preocuparse mucho de los resultados efectivos de esos eventos y probablemente en esto muestran un resto de sabiduría. Porque si en el mundo actual los adultos responsables de sus derechos ciudadanos y concientes de las apuestas políticas del presente pueden observar casi a diario el valor prácticamente nulo de sus protestas y la marcada ausencia de interés manifestadas por parte de las autoridades respecto a sus inquietudes, parece totalmente vano esperar que las palabras de niños y adolescentes sean tomadas en cuenta para definir las grandes orientaciones del devenir globalizado.

Pero no es el punto. Mucho más grave parece el autoengaño de los adultos - ¿o será que en sus adentros ni se lo creen?- al opinar que un

\footnotetext{
* Docente la Maestría en Política Social para la Promoción de la Infancia y Adolescencia de la Universidad Politécnica Salesiana del Ecuador y Docente de la Pontificia Universidad Católica del Ecuador.

${ }^{1}$ B. Bettelheim, Carta a M. Chapsal, citado en Nina SUTTON (1996), Bruno Bettelheim, une vie. Hachette, París, p. 508. (Traducción nuestra).
} 
niño o una niña antes de la adolescencia es capaz de entender la sociedad más allá de su experiencia inmediata. El pensamiento infantil no es idéntico al de los mayores; y del desconocimiento de esas diferencias nacen muchos de los malentendidos que fácilmente conducen a una destrucción de la niñez en su esencia de momento transitorio aunque indispensable en la estructuración del sujeto en su camino hacia la mayoría de edad, cuando se volverá responsable frente a la Ley. Ya hace mucho tiempo Ferenczi, discípulo favorito de Freud, hablaba de la 'confusión de las lenguas' entre las generaciones y consideraba que era un factor de gran violencia contra los niños².

En este sentido todos los adultos preocupados por cuestiones relativas a la infancia deberían darse la oportunidad de pensar en los niños no tales como ellos se los imaginan sino tales como se manifiestan y se expresan en la realidad cotidiana. Piaget en este sentido ofrece unas investigaciones rigurosas sobre el desarrollo cognitivo y la construcción intelectual del pensamiento humano, permitiendo acercarnos de manera muy palpable al razonamiento y a la mirada infantil sobre el mundo que le rodea.

Nociones que para el común de la gente parecen categorías innatas como el espacio, las dimensiones, el tiempo, las percepciones, no dejan de ser profundamente elaboradas culturalmente; lo que nos indica dos cosas, la una es que resultan de aprendizajes, la otra es que no se adquieren de golpe sino más bien de manera paulatina con la educación casera en los primeros años y luego a través de la escuela. Por ende un niño de 4 años no percibe su entorno de la misma manera que uno de 8 años y tiene una cosmovisión muy diferente de la de un chico de 11 años. Sin embargo hay que recordar que el gran giro en la manera de pensar y de entender el mundo no se da antes de la adolescencia, en la pubertad, cuando el joven empieza a manejar el pensamiento abstracto que le permite reflexionar sobre problemas hipotéticos y hacer suposiciones respecto a situaciones que no ha vivido personalmente; a la vez que su relación con sus pares va a ser totalmente modificado por lo real de los impulsos sexuales y la atracción por los cuerpos otros.

\footnotetext{
2 S. Ferenczi [1933]. "Confusión de lenguas entre los adultos y los niños". Obras completas, Psicoanálisis IV.
} 


\section{La primera niñez, un período tormentoso}

La pugna entre las fuerzas pulsionales y el anhelo de cumplir lo mejor que pueda con los supuestos deseos y las demandas del adulto que encarna al Otro, constituye el motor principal del desarrollo infantil. Por esta razón, lejos de ser armónico, se pauta con una alternancia entre conflictos y soluciones que abren en cada etapa la posibilidad de un acceso a una nueva dimensión de la realidad. De este modo la estructuración psíquica normal del niño es el efecto de progresivas integraciones que van a marcar momentos en su crecimiento y llevarle a ser un adulto integrado en su sociedad.

"El niño necesita que se le dé la oportunidad de comprenderse a sí mismo en este mundo complejo con el que tiene que aprender a enfrentarse, precisamente porque su vida a menudo le desconcierta ... Debemos ayudar al niño a que extraiga un sentido coherente del tumulto de sus sentimientos. Necesita ideas de cómo poner en orden su casa interior... Necesita... una educación moral que le transmita, sutilmente las ventajas de una conducta moral, ...mediante lo que parece tangiblemente correcto $y$, por ello, lleno de significado para el niño $o^{3 .}$

La ausencia de leyes y de valores éticos no tiene efectos solamente comportamentales sino también psíquicos que complican mucho el proceso de estructuración subjetiva. En el plan intrapsíquico, los niños de edades oscilando entre los 3 y los 6 ó 7 años pasan por una época de grandes borrascas afectivas- el llamado complejo de Edipo- durante la cual están sujetos a devastadoras emociones y sentimientos intensos y ambivalentes de amor y de odio hacia las personas más cercanas, en particular los padres y los hermanitos. En esta etapa sumamente importante para su desarrollo, necesitan más que nunca el apoyo firme y a la vez cariñoso de su familia y sobre todo de un padre que acepte jugar el papel de malo de la película cuando sea necesario, es decir que tenga la fuerza de reprehender e incluso a veces de castigar al niño cuya violencia interior puede llevar a cumplir actos peligros o excesivamente destructores contra sí mismos o contra los otros.

${ }^{3}$ B. Bettelheim (1984). Psicoanálisis de los cuentos de hadas. Grijalbo. Barcelona. P.12. 
Porque a pesar de los sentimientos violentos que les atormentan, los niños quieren más que todo complacer a sus padres y a sus sustitutos, y por esto mismo buscan hacer lo mejor que puedan para merecerse su cariño y más que todo no perder su amor. Aunque a menudo desconocido por los adultos, el deseo del bien, es decir de hacer todo bien para satisfacer a los adultos es un motor esencial en el desarrollo del niño y en sus actuaciones.

\section{Los niños necesitan diferenciar el bien y el mal}

Sin embargo la noción de bien no es innata y, a diferencia de un adulto, la idea que un niño se hace de lo que está bien y de lo que está mal esta totalmente supeditada a los imperativos y a las demandas de sus padres, por lo más distorsionado que sea el modo de actuar de aquellos ${ }^{4}$. Esto explica, por ejemplo, porqué niños en situaciones de maltrato grave no solo aceptan los golpes sino que los entienden como expresiones de amor, lo que luego los llevará a repetir situaciones en las cuales serán violentados y agredidos, o a su vez transformarse en victimarios, confirmando de este modo la existencia de una relación de amor, de la misma manera que sus progenitores se lo manifestaron anteriormente ${ }^{5}$

En el contexto de valorización afectiva y cultural de los comportamientos y de los actos, el desarrollo y la apropiación de criterios morales constituyen un elemento esencial para la integración del infante en un mundo humanizado tanto como para dar a sus acciones orientación y sentido.

La adquisición de valores éticos se inicia con la aparición de criterios distintivos entre lo bueno y lo malo, manifestados por la aparición de los primeros juicios cualitativos bajo la forma de "Como lo bueno, escupo lo malo". Esta primera discriminación fundamenta la estructuración subjetiva arcaica de los primeros meses, para luego desembocar en la diferenciación de lo que está permitido y lo que está prohibido después de un complejo proceso psíquico. Luego, en el período de los 3-5 años, la estructuración

\footnotetext{
${ }^{4}$ Sobre la construcción del pensamiento moral en el niño, ver J. Piaget [1932]. El criterio moral en el niño.

${ }^{5}$ Pierre Kammerer (1996). Violence et institution à l'adolescence: travailler à partir des passages à l'acte, en DIALOGUE n' 131, 69-91.

${ }^{6}$ S. Freud (1925). La denegación.
} 
subjetiva se ve sometida a un fuerte proceso de socialización marcado y moldeado por los matices culturales de la sociedad en la cual vive y crece el niño. A partir de entonces la introyección de los valores propios a su grupo social va a permitirle una progresiva integración y adaptación a un entorno de vida, y un fortalecimiento de sus relaciones con pares, posibilitando de este modo una futura participación placentera y dinámica en la vida de su comunidad.

Desgraciadamente el mundo actual es muy reacio a aceptar la necesidad de valores éticos para vivir en sociedad, más allá de la referencia omnipresente al dinero como medida única; para algunos, los criterios morales son residuos superfluos de tiempos obsoletos; para otros se han transformado en adornos de la personalidad y en objetos de consumo que se pueden adquirir en un supermercado, bajo la forma de libros de autoayuda por ejemplo. Es olvidar que toda sociedad se apoya en y se organiza alrededor de una serie de "referencias fundadoras" que, de una forma explícita o no, articulan las leyes y reglamentan el sistema de valores, creando de este modo un orden que permita la convivencia de los miembros del grupo, orden fálico por excelencia.

$\mathrm{Al}$ ahondar esta reflexión, cabe notar que la segunda mitad del siglo veinte se ha caracterizado por un fuerte cuestionamiento a todo sistema de valores, sobre todo en su dimensión ética y a su organización patriarcal asimilada a una supuesta opresión por parte de los hombres. En este aspecto, 'Mayo 68' ha tenido secuelas graves y duraderas, y las contradicciones propias al mundo moderno se reflejan en una proliferación de sectas con sus creencias esotéricas en lugar de las grandes religiones tradicionales basadas en una concepción del mundo entendible e interpretable. Más aún, una tal situación de anomia y la ausencia de un orden social fomentan conductas psicopáticas y delincuentes de jóvenes en mal de leyes claras para orientar su vida. No faltan observaciones clínicas que muestran hasta qué punto educaciones sin rumbo ético, donde lo permitido y lo prohibido se vuelven expresiones fugitivas de lo arbitrario materno, son el semillero de comportamientos infantiles "aberrantes", antes de propulsar a los adolescentes en una búsqueda desesperada de sentido a través de pasajes al acto mortíferos.

\footnotetext{
${ }^{7}$ Pierre Legendre (2001). De la société comme texte. Linéaments d'une Anthropologie dogmatique. Fayard. Paris.

${ }^{8}$ Retomo la expresión a Laetitia y Jean-Pierre Chartier, Les enfants et les adolescents agresseurs sexuels, en M. Gabel coord. (1992). Les enfants victimes d'abus sexuels. PUF, Paris, p.135.
} 


\section{Metáfora paterna, socialización y educación}

En el proceso de maduración, la función paterna -el 'nombre del padre'- juega un rol fundamental en cuanto para el niño determina una referencia fundadora, un punto de anclaje, un ordenador de los discursos y de los saberes; y a la vez sirve de protección frente al peligro de ser engullido por el deseo materno y reincorporado fantasmáticamente en su seno. "El deseo de la madre, dice Lacan con su estilo barroco, no es algo que uno puede soportar así no más... Un gran cocodrilo en cuya boca Uds. está, eso es la madre. Nunca se sabe lo que le puede ocurrir de repente, cerrar su tapa. Existe un rodillo... está en potencia al nivel de la tapa, que se detiene, se atasca. Es el falo, es el rodillo que le pone a resguardo por si acaso eso se cierre". . Y este falo, este objeto capaz de detener la gula materna, lo posee el padre, capaz de tranquilizar o de enfrentarse a la omnipotencia de la mujer. En este proceso de poner límites a la madre, la figura paterna cobra todo su valor: ese padre es alguien de quien la madre tiene cuenta, alguien importante en las decisiones que ella toma respecto a sí misma y respecto a sus hijos.

El caso que la madre hace de la palabra del padre y la manera cómo la transmite son muy significativos de la dinámica familiar imaginaria; reflejan el valor atribuido a cada pieza en el tablero familiar y sobre todo determinan el papel simbólico del padre en las interrelaciones estructurantes para el niño.

En un plan más elaborado, la constitución de un orden moral para el niño - “el llamado Superego del psicoanálisis"- toma apoyo inicialmente en una figura externa, es decir alguien quien se haga cargo de las pulsiones agresivas del pequeño sujeto, jugando el papel de Bad Guy, de ogro, para absorber, en un mecanismo proyectivo, los sentimientos de maldad y las pulsiones destructoras del niño que le permite de este modo procesarlos sin sentirse abrumado y aplastado por tantas iras y deseos mortíferos hacia su entorno. En este sentido para ocupar su función frente a su hijo el padre debe aceptar este rol vicariante frente a todo lo que puede ser vivido como peligro interior por parte del niño tanto como frente a las amenazas externas. Desgraciadamente en la mitología de la modernidad los hombres ya no quieren ocupar este papel. A menudo pre-

${ }^{9}$ J. Lacan (1991). Le séminaire livre XVII, L'envers de la psychanalyse, Seuil, Paris, p.129. (Traducción nuestra) 
fieren comportarse como otros hijos, al menos que se sientan más cómodos en posición de extraños cuya sombra viene a irrumpir de vez en cuando en la tranquilidad del nido familiar.

\section{Los padres ya no quieren ser padres}

Aquí nos topamos con una primera dificultad de gravedad para la estructuración de los niños: los padres -y hablo del varón- ya no quieren ser padres porque no quieren renunciar a ser hijos: "Cuando un humano se vuelve padre, no está subjetivamente en este puesto automático de padre respecto al recién llegado, debe conquistar este puesto, renunciando a su propio estatuto de niño. Debe morirse a su condición de niño para cederla a su hijo" ${ }^{10}$.

En el contexto actual de ocaso de la función paterna y de cuestionamiento al orden 'patriarcal', muchos hombres temen asumir responsabilidades adultas y hablar en nombre propio; rehúsan abandonar el regazo materno que hasta entonces les había asegurado consuelo y protección.

Desde hace mucho tiempo, ya desde Freud, se sabe que la psicosis se relaciona con un vacío, un interrogante o una falta de estructuración simbólica de la figura paterna, cuando, por ejemplo, se desencadena una crisis delirante en un hombre cuya compañera acaba de anunciarle una futura paternidad. Sin ir tan lejos, en la época actual, muchos hombres viven la posibilidad de ser padres como un cuestionamiento y una amenaza a sus privilegios de niño-rey y huyen de la posibilidad de entrar en una relación de filiación y de rivalidad con un hijo que les vendría a profetizar el fin de su reino en algún tiempo futuro, temas muy comunes en los mitos ${ }^{11}$, pero que ahora, a falta de simbolización, retornan en lo real.

De ahí, no hay que extrañarse de la aparición de niños huérfanos de padres a pesar de tener a un papito en la casa. Una de las consecuencias más inmediatas de esta situación es que el niño se sienta totalmente desarrimado, sin un anclaje en su vida que le permita organizarse fren-

${ }^{10}$ P. Legendre (1989). Le crime du caporal Lortie. Fayard, Paris, p. 67. (Traducción nuestra).

${ }^{11}$ O. Rank (1981). El mito del nacimiento del héroe. Paidos Studio, Buenos Aires. 
te al océano de los deseos femeninos y maternos y no "perderse como objeto del goce del Otro" 12 .

\section{Y las mujeres ...}

Si muchos hombres en el mundo presente ya no quieren asumir una función paterna por motivos propios, hay que reconocer que a menudo se ven animados en su renuncia por las mismas mujeres quienes, en su cuestionamiento al orden 'patriarcal', quieren serlo toda, reunir entre sus manos todas las funciones tanto femeninas como masculinas, y detener un poder de decisión absoluto sobre los requerimientos de sus hijos sin tener que remitirse a ningún tercero: "El tiempo me dará la razón en mi manera de educar a mi hijo" decía una mujer al psicólogo que le intentaba explicar la importancia de una separación afectiva y corporal entre ella y su hijo adolescente.

Al examinar las nuevas legislaciones respecto a la familia, se observa cómo la mujer poco a poco ha acumulado todos los poderes respecto a los hijos, y en particular el de decidir de la filiación de su prole. De modo que la relación madre/hijo se vuelve completamente dual, sin mediación, sin la posibilidad para un tercero, que sea el genitor, el Estado, o siquiera una teoría, una ideología, de intercalarse entre los dos protagonistas ligados en un enfrentamiento eterno y mortífero. No es que la madre no pueda ayudar al niño a construirse una metáfora paterna, un baluarte defensivo contra su apoderamiento de la vida psíquica de su hijo; aunque, por tratarse de una protección contra una sujetación sin límite a su deseo de madre, le resulta mucho más difícil sin la ayuda de un padre.

Por otra pare, a falta de alguien que pueda o acepte ocupar el lugar de padre, a los hijos solo les queda como destino cumplir con las expectativas maternas sin ningún resquicio por donde expresar un deseo propio; por ende la estructuración subjetiva se vuelve problemática y el niño queda atrancado en una posición infantil.

${ }^{12}$ C. Calligaris (1991). Pour une clinique différentielle des psychoses. Point Hors Ligne, Paris, p.17. 


\section{Los niños en la jaula de su madre}

El primer desarrollo de un niño está íntimamente enlazado con la estructura psíquica materna; en particular las investiduras afectivas de las cuales es objeto por parte de su madre, la calidad del vínculo de aquella con un hombre, el padre, y la manera cómo ella se adscribe a un saber relativo a la maternidad. Cuando el recién nacido no representa para la madre ninguna ilusión de futuro, ni viene a significarle nada de un deseo de don de hijo o de hija a un padre en retribución a su acceso a la feminidad, ni reviste un valor simbólico de inscripción en una comunidad, este niño se ve abocado a servir exclusivamente los intereses pulsionales de esta madre; como si creciera en un mundo limitado a él y a ella, en una célula autosuficiente, la cual puede a veces pero no necesariamente absorber a otros hermanos e incluso a un padre-hermano, en un mundo sin socialización. Esta situación dificulta muchísimo la estructuración psíquica del niño porque tiene entonces como única referencia a su madre, ella misma en posición de desarticulación respecto a su grupo sociocultural.

En los casos más graves de exclusión psicosocial, Dumesnil ${ }^{13}$ propone tres perfiles de niños, cuyo desarrollo se caracteriza por la falta o la distorsión de la investidura materna: el niño de la carencia, el niño de la pulsión y el niño del conflicto.

El niño 'de la carencia' nunca fue objeto de solicitud materna porque, cuando él la necesitaba de sobre manera, ella estaba encerrada en su propia búsqueda narcisista sin capacidad para interesarse por su hijo. En ciertos casos, en particular cuando se trata de una madre depresiva, el bebé, privado de todo investidura materna, en una relación de desconocimiento total por parte de ella ${ }^{14}$, desarrolla un síndrome autístico; como este niño cuya madre no se acordaba haber estado embarazada, después de su parto por cesárea, o esta otra madre que comenta que su hijo le parecía 'un pedacito de carne'.

${ }^{13} \mathrm{Fr}$. Dumesnil (1993). Au coeur des psychoses précoces: le traitement relationnel. PUF, Paris, p.67ss.

${ }^{14} \mathrm{Ver}$ al respecto $A$. Jerusalinsky (1992). Autisme: l'enfance du réel, un temps sans espace, un espace sans temps, un paradoxe sans discours. En La clinique de l'autisme, Fondation Européenne pour la Psychanalyse, Point Hors Ligne, Paris. 
En otros casos, para compensar el vacío afectivo, esos niños se esfuerzan en cada momento por llamar la atención, lo que es su modo de hacerse presentes para los otros. La mayoría de los niños hiperactivos pertenecen a esta categoría ${ }^{15}$, indicándonos así que no se trata de una patología específica sino de un efecto de la (pos)modernidad y del actual narcisismo extremo por el cual la madre no puede desprenderse de su hijo, un mero apéndice de ella, imposibilitándole de este modo relacionarse con los otros en base al reconocimiento de la alteridad, del semblante diría Lacan. Un ejemplo clínico ilustra esta situación. Un niño varón de unos seis años desfila de psicólogo en psicólogo desde los tres años "porque, dice la madre, ya no lo soporto"... El diagnóstico es de hiperactividad, aunque desde un punto de vista psicoanalítico se trata de una psicosis infantil caracterizada. El niño que lleva de segundo nombre el de un personaje histórico muerto de forma violenta tiende a provocar a los compañeritos hasta que le agredan. Solo se tranquiliza y queda quieto cuando, en ausencia de la madre, se vuelve el punto de mira de un adulto quien de este modo le viene a dar un lugar y unos límites corporales. Hace varios dibujos de muertos por caerse de un edificio, su manera de cuestionar el deseo de su madre hacia él: "Tengo terror de que se abalance" dice ella (viven en un cuarto piso), manifestando de esta forma "los deseos de muerte de una madre que puede parecer preocupada" $"$, en ausencia de una metáfora paterna que ponga límites a su relación con su hijo. Al nacer este niño más de 10 años después de sus hermanos y después de dos abortos, el padre que no deseaba tener a otro hijo dijo a la madre: "eso es asunto tuyo".

El otro tipo de niño es el 'de la pulsión'. Son niños cuya investidura afectiva se dio meramente en un plan de satisfacción de necesidad, es decir para responder a los requisitos afectivos, emocionales y psíquicos de su madre; esta situación se da fácilmente en madres adolescentes que todavía no han encontrado un equilibrio psíquico. En esos casos el actuar remplaza la mentalización: todo se hace en lo inmediato, en lo concreto, sin que haya espacio para una palabra estructurante o tranquilizadora. Más aún a menudo el niño está vivido por su madre como la expresión de sus sentimientos y de sus necesidades a ella, a

${ }_{15} \mathrm{~J}$. Bergès (1979). Troubles psycho-moteurs et relaxation chez l'enfant. En Psychologie Médicale, 1980, 12, 7, p. 1513ss.

${ }^{16}$ B. Bettelheim, ibid, p. 508. 
veces objeto persecutor en el cual ella proyecta su agresividad a través de un saber distorsionado - este bebé (un recién nacido) grita a propósito para molestarme - o a la inversa objeto transicional, peluche de su madre sin sensaciones o deseos propios, como para esta madre que despierta a su bebé en plena noche porque decide que tiene hambre y que debe tomar la teta. Para esos niños de la pulsión, el futuro deja entrever un inquietante pronóstico de conductas perversas o de delincuencia porque no logran construirse una representación psíquica estable de sí mismos y sus mociones pulsionales se desparraman en actuaciones puntuales, sin poder unificarse bajo el predominio de una realización personal (la llamada genitalidad) ${ }^{17}$.

Por fin cabe considerar a los niños 'del conflicto'. Si los dos primeros perfiles que presentamos apuntan a patologías muy tempranas, consecuencias de actitudes y problemáticas maternas graves, el niño del conflicto responde a una dinámica específica de los padres que utilizan a sus hijos para manifestar sus propios conflictos frente a la vida y al entorno. En estos casos el bebé, sí, ha sido objeto de solicitud y de atención por parte de una madre a menudo acompañada por un padre, o incluso a veces fue criado por un padre y la abuela por ejemplo. Pero al crecer, toda su educación, en lugar de ayudarle a desarrollar una subjetividad personal, va a ser orientada para transformarle en un adulto en miniatura, sea que él mismo se haga cargo de sus padres, sea que actué en delegación a lo que ellos le impongan como metas, ignorando tanto sus necesidades propias cuanto las condiciones reales de su existencia, edad y vivencias específicas. Como este niño de seis años cuyo padre le obligaba a hacer exactamente lo contrario de todo lo que los maestros le enseñaban, como sentarse con la silla al revés, bajo el pretexto que él -el padre- había sido muy reprimido en su infancia; o este otro ejemplo de un padre que explicaba con orgullo cómo había acostumbrado a sus hijos de nueve y siete años a ver la televisión como castigo auto-impuesto.

\footnotetext{
${ }_{17}$ Ver el artículo sobre menores agresores sexuales, antes mencionado de L. y J. - $P$ Chartier en en M. Gabel coord. (1992). Les enfants victimes d'abus sexuels. PUF, Paris, así como Cl. Balier. Psychopathologie des auteurs de délits sexuels concernant les enfants. (1992). Id. p.149ss.
} 


\section{Niños envejecidos, adultos infantilizados}

Desde una perspectiva de trastornos de la parentalidad, se pueden observar casos en los cuales son los niños que se reponsabilizan de sus padres, en una relación invertida; son niños y más a menudo niñas primogénitas que se hacen cargo de las tareas que corresponden a sus padres, no solo en el plan material sino sobre todo en el plan afectivo y emocional. Este tema es conocido por la literatura psicológica y psicoanalítica, pero poco estudiado y velado por un silencio difícil de explicar. Por fin hay que mencionar a las personalidades 'como si' que ofrecen un perfil muy reconocible de niños y jóvenes muy dotados en general, pero incapaces de manifestar emociones, porque toda su vida afectiva ha sido sujeta a una profunda inhibición; se tratan de infancias privadas de amor por parte de los padres, lo que les impide a su vez toda expresión de sentimientos fuera de la racionalidad ${ }^{18}$. Es probable que se observe este tipo de situación cada vez más a menudo, por la tendencia posmoderna a lo que podemos llamar "el infantilismo de la sociedad"19.

Por otro lado, con una preocupación creciente y una sensación de impotencia, todos observamos cómo nuestro mundo, nuestro planeta, se nos está yendo de las manos y se deteriora a gran velocidad para transformarse en un lugar muy inhóspito. En el plan político, a partir de un cierto nivel, uno se siente inmerso en una total incapacidad de producir cambios y de fomentar mejorías socioculturales; incluso la producción artística muestra un gran estancamiento ${ }^{20}$. En este contexto no hay que extrañarse de que los adultos anhelen renunciar a sus responsabilidades. Para el efecto tienen a la mano dos soluciones a menudo complementarias. La una es refugiarse en una de esas sectas esotéricas y milenaristas desvinculadas de la realidad cotidiana, establecidas sobre principios etéreos y sin relación con la existencia real. La otra es negar su propia maduración psíquica e imaginarse como infantes crecidos sin que su manera de pensar sea diferente de aquellos: "Deja hablar al niño

\footnotetext{
${ }^{18}$ El término de 'como si' fue acuñado por H. Deutsch [1942) en su libro Psicoanálisis de las Neurosis: "Distintos trastornos afectivos y su relación con la esquizofrenia".

${ }^{19}$ Ver al respecto el libro del filósofo, P. Bruckner, La tentación de la inocencia. ${ }^{20} \mathrm{~B}$. Stiegler, Le désir asphyxié, ou comment l'industrie culturelle détruit l'individu.
} 
que tienes adentro"; porque así sus palabras ya no llevarían a más consecuencias que las de chiquillos. En cambio a los niños se les atribuye palabras premonitorias y un don de profecía, con el encargo de decir la bienaventuranza al mundo, como en muchas películas de suspenso.

\section{Los niños no tienen una orientación sexual}

Un paréntesis antes de terminar. Si la mayoría de los padres y de las madres, por el sentido común y por un verdadero amor, evitan a sus hijos destinos de desadaptación afectiva y social, no siempre logran escapar a los discursos de moda, creando graves perjuicios en el desarrollo de sus hijos y en particular en la estructuración de su sexualidad. Uno de los grandes lemas de la posmodernidad es la pretendida indiferenciación sexual entre hombres y mujeres, sostenida por algunos planteamientos feministas extremos, y retomada de forma implícita por los promotores del matrimonio homosexual. Si a estos discursos se añade la reducción genetista de todo comportamiento humano a un programa de ADN, la sexualidad pierde su significación y la estructuración subjetiva se ve distorsionada.

De ahí no nos podemos extrañar de ciertos propósitos absurdos en cuanto a la sexualidad infantil, propósitos del estilo "Tal niño de 8 años dibuja todo rosado porque va a ser 'gay'”. Como vimos anteriormente, el pretendido saber de una madre sobre su hijo es para él una trampa difícil de sortear y por ende predicciones de esta índole tienen efectos devastadores en el niño o la niña que se ve abocado a responder a esta demanda materna, aunque signifique renunciar a ser uno mismo, hipotecando de este modo su propio deseo de vida. Sin entrar en el análisis clínico del comportamiento del chico antes mencionado que reservamos para un próximo trabajo, es esencial recalcar que los niños no tienen una orientación sexual que les lleve a desear como tal un objeto exterior; porque hasta la pubertad sus impulsos sexuales no los atraen hacia otra persona; están inmersos en el fortalecimiento de su narcismo indispensable para su maduración afectiva, y su interés por el cuerpo de los otros, es estrictamente especular, en plan de juego y de curiosidad, una manera de conocerse a sí mismo en comparación con el cuerpo ajeno, entre similitudes y diferencias.

A menos... a menos que hayan sido abusados sexualmente, porque los niños abusados son niños envejecidos de golpe, privados brusca- 
mente de su capacidad de juego, de sueños, de imaginación y fantasías, excluidos del período de latencia tan rico y tan necesario para la elaboración de una posición subjetiva. Son niños atrapados en lo real de su sexo que ya no puede servirles de asidero para construcciones fantasmáticas. Solo un trabajo terapéutico podría devolverles por lo menos la ilusión de un devenir adulto y del amor, a falta de un uso más satisfactorio de su sexualidad.

\section{Un rayo de luz}

Al terminar una reflexión, es mejor no quedarse en el tono de la lamentación que denota cierto facilismo masoquista, y más bien intentar vislumbrar alguna salida aunque el camino este todavía lleno de malezas. El hurto de infancias no es un fenómeno contingente sino que responde a la corriente de la posmodernidad, faceta ideológica del neoliberalismo y de la razón de mercado, las principales fuerzas que determinan el rumbo de las sociedades actuales; y el consumismo, necesario para sostener la lógica de este modelo económico, va a la par con un narcisismo extremo que destruye los lazos familiares y sociales. En esta perspectiva es normal que los padres no quieran ser padres, que las madres no quieran criar a hijos y que por ende los niños ya no puedan ser niños porque no les está permitido jugar en serio y menos aún soñar a futuro sino que se ven precipitados en la vorágine capitalista de destrucción de identidad simbólica.

La pregunta es entonces ¿cómo devolver a los jóvenes una niñez que les permita construirse poco a poco como seres en devenir, sin cortocircuitos emocionales, sin pensamiento artificialmente madurado, sin falsas actitudes de precocidad sexual, sin la pseudo-creencia de "Consumo, luego existo"?

Desde el alba de los tiempos, el ser humano ha sido dividido entre los intereses individuales de placer y autoconservación por una parte y, por otra, el sometimiento necesario al bien de la colectividad, única vía de sobrevivencia a la vez subjetiva y transgeneracional. La integración de esas instancias psíquicas dependía otrora de la socialización de los niños, apoyada por propuestas y modalidades educativas muy variadas que les ayudaban a desarrollar sus potencialidades individuales imaginarias, dentro y en favor del reconocimiento de un ideal común al grupo. 
Sin embargo, la máquina aplastadora de la globalización ha acabado con el equilibrio entre lo individual y lo colectivo, que ha tornado frágil el proceso de socialización, creando un hombre 'unidimensional', como decía Marcuse, monolítico, sin capacidad creadora, porque está reducido a reproducir al infinito lo mismo y aglutinarse con los otros en placeres de masa en nuestra época de 'fin de la Historia'. Se entiende entonces porqué en este ambiente de vacío sociocultural la tarea parental de educar a los hijos se vuelve cada vez más imposible. Por suerte, existen todavía algunas personas, héroes anónimos del mundo presente, que creen en el valor formador y humanizante del aprendizaje: son los maestros, convencidos del poder de la letra y de la cultura para crear mundos mejores y más equitativos, los más aptos para ayudarles a crecer, podrían sustituirse a los padres posmodernos desfallecientes, siempre y cuando aquellos acepten desprenderse del usufructo de sus hijos.

Para esto, necesitamos a maestros capaces tanto en el plan intelectual como emocional y ético, verdaderos educadores, nuevos mistagogos de la vida, deseosos de acompañar a los jóvenes durante su infancia para conducirles hacia una integración social y una participación cultural por la vía de una realización personal que sea también la de todos. 
